\title{
A STUDY ON SILICA SAND QUALITY IN YAZARAM AND MUGULBU DEPOSITS FOR GLASS MAKING
}

\author{
G. A. Duvuna ${ }^{1}$ and A. Ayuba ${ }^{2}$ \\ 1,2, Department of Mechanical Engineering, Federal Polytechnic, Mubi. Adamawa State, NiGeria. \\ E-mail Addresses: ${ }^{1}$ gideonayubaduvuna@yahoo.com, ${ }^{2}$ aryhelayuba@gmail.com
}

\begin{abstract}
The suitability of silica sand deposits of Yazaram and Mugulbu in Mubi South Local Government Area of Adamawa State, Nigeria for commercial glass production were assessed based on the chemical and physical properties of the silica sand samples collected along the river side's. Test was carried out at the National Metallurgical Development Centre (NMDC), Jos. The chemical analysis was carried out using X-ray florescence spectrometer (XRFS) and the physical properties such as the particle size, grain morphology and the specific gravity examinations were carried out using mechanical shaker (sieving method), electronic microscope to reveal the shape of the samples and the specific gravity testing machine respectively. The results obtained were assessed and compared with the standard requirements for glass making. Mugulbu had the highest percentage of silica content of $77.70 \%$ and Yazaram had the lowest percentage of silica content of $77.60 \%$ and the grain morphology was found to be angular with specific gravity of 2.50 for both the samples, which were found to be within the acceptable limits for glass making. The iron oxide content in all the samples was found to be high, with highest value of $1.94 \%$ for Mugulbu and lowest value of $1.05 \%$ for Yazaram. However, the iron content for all the samples was above 1\% thereby limiting the range of applications to coloured and amber glass manufacturing. The physical properties for all the samples were found to satisfy the standard requirements for glass making.
\end{abstract}

Key words: Grain morphology, specific gravity, physical property, chemical property, silica sand, glass, iron oxide.

\section{INTRODUCTION}

Sand consists of small grains or particles of minerals and rock fragments. Although these grains may be of any mineral composition, the dominant one of sand is the mineral quartz, which is composed of silica (silica dioxide). Other components may include aluminum, feldspar and iron with particularly high silica levels is referred to as silica sand [1]. For a particular source of silica sand to be suitable for glass making, it must not only contain a very high proportion of silica but also should not contain more than strictly limited amounts of certain metallic elements [2,3].

The presence of metallic oxides in silica sands usually results in coloured glass. If iron is present, the resulting glass is coloured. The iron level is consequently the most critical parameter in determining whether a particular sand can be used to make clear or coloured glass [4]. According to [5], window glass sand may contain $0.1 \%$ to $0.5 \%$ iron oxide $\left(\mathrm{Fe}_{2} \mathrm{O}_{3}\right)$ and dark green bottle glass as much as $2 \%$ to $3 \%$ iron oxide. For colourless glass containers, generally, the sand may contain less than $0.035 \%$ $\mathrm{Fe}_{2} \mathrm{O}_{3}$, for flat glass in the range of $0.040 \%$ to $0.1 \%$ $\mathrm{Fe}_{2} \mathrm{O}_{3}$ [6]. [7], reported that, most glasses have roughly similar chemical composition of $70 \%-74 \%$ $\mathrm{SiO}_{2}, 12 \%-16 \% \mathrm{Na}_{2} \mathrm{O}, 5 \%-11 \% \mathrm{CaO}, 1 \%-3 \% \mathrm{MgO}$, $1 \%-3 \% \mathrm{Al}_{2} \mathrm{O}_{3}$, within these limits the composition is varied to suit particular product and production method.

Grain-size distribution or grain shape is another important factor in glass making. According to [1], the grain size should lie within a given size limit and must be uniform. The ideal size of the grains should be between 0.1 and $0.5 \mathrm{~mm}$ in diameter or between 15 100 mesh (BSS number) and it is required that $75 \%$ of the grain should fall within this range[4]. Grain morphology is another physical property that determines the suitability of the silica sand for glass

* Corresponding Author, Tel: +234-805-683-3078 
making. According to $[5,8]$ the roundness of the grain must be angular rather than rounded. [9] reported that, minerals with specific gravity greater than 2.65 cannot be suitable for glass making. These types of minerals exist as inclusions in a finished glass and can survive the glass melting process and come out as solid or stone defects.

Glasses may be devised to meet almost any imaginable requirement for many specialized applications. According to [7], glass can be made by melting together several minerals at very high temperature. Silica sand by itself can be fused to produce glass, but the temperature at which this can be achieved is about $1700^{\circ} \mathrm{C}$. The addition of sodium carbonate $\left(\mathrm{Na}_{2} \mathrm{CO}_{3}\right)$ known as soda ash, to produce a mixture of $75 \%$ silica $\left(\mathrm{SiO}_{2}\right)$ and $25 \%$ sodium oxide $\left(\mathrm{Na}_{2} \mathrm{O}\right)$, will reduce the temperature of fusion to about $800^{\circ} \mathrm{C}$.

The uses and application of glass in today's technology are numerous, therefore, investigation of the chemical and physical properties of Yazaram and Mugulbu silica sand in Mubi South,Adamawa State, which is characterized by vast sand deposits for glass making is of paramount importance.

\section{MATERIALS AND METHOD}

Two samples of silica sand were collected along different stream sides of Mubi South Local Government of Adamawa State namely Yazaram and Mugulbu. Test on chemical and physical properties of the silica sand samples were carried out at the National Metallurgical Development Centre,Jos, Plateau State, Nigeria [10].

The silica sand samples were first cleared coned and quartered to obtain the representative fraction. The coning and quartering involved pouring the silica sand samples on the flat surface, such that it formed a cone which was divided into four equal parts by using a straight edge [11]. The two alternate quarters were mixed again for further quartering. After which the representative fraction for each sample was later crushed and ground separately to pass through 120 mesh (BS) sieve. This ground silica samples were then used for the chemical analysis, which is in line with the work of [12].

\subsection{Chemical Analysis}

An $\mathrm{x}$ - ray florescence spectrometer (XRFS) was used for the analysis. $\mathrm{X}$ - Ray florescence spectrometer is a non destructive analytical technique used to identify and determine the concentration of elements and compounds present in solid or liquid samples. The samples for the analysis are required to be presented to the spectrometer in a homogeneous reproducible form either milled or ground to give a flat surface.

The silica sand samples which were earlier prepared were further ground and sieved to $75 \mu \mathrm{m}$ particle size. $4 \mathrm{~g}$ of the sieved samples was intimately mixed with $1 \mathrm{~g}$ of lithium tetraborate binder $\left(\mathrm{Li}_{2} \mathrm{BO}_{4}\right)$ and passed in a mould under a pressure of $10-15$ tonnes/in ${ }^{2}$ to a pellet. The pressed pellets were dried at $1100^{\circ} \mathrm{C}$ for 30 minutes in an oven to get rid of any absorbed moisture and were finally stored in desiccators for analysis. The spectrometer was switched on and allowed to warm up in order to stabilize the optics and the $\mathrm{x}$ - ray tube. It was then calibrated to determine the expected elements or compounds present in the silica sand.

\subsection{Particles Size Analysis}

Dry sieving method was adopted and the represented silica sand samples were obtained from the quartered silica sand samples. The samples were first dried in an oven and from each sample; $100 \mathrm{~g}$ was weighed and arranged on a mechanical shaker with the coarsest on top. The machine was operated for 15 minutes. After sieving the samples, they were emptied onto sheets of paper and weighed one after the other, and then the cumulative percentage by weight of the particles passing each sieve was calculated and recorded.

\subsection{Grain Morphology Test}

The shape of the silica sand determined the suitability of the silica sand sample for glass making. The silica sand samples were viewed under electronic microscope to reveal the shape of the samples and their suitability for glass making.

\subsection{Specific Gravity Examination}

The specific gravity was obtained directly from the specific gravity tester. The silica sand samples were introduced into the machine, which automatically carried out the test and displayed the values of the specific gravity digitally on a visual display unit.

\section{RESULTS AND DISCUSSION}

Tables I, II and III shows the chemical composition, physical properties and the calculated cumulative percentage weight of the silica sand particles passing each sieve aperture of the samples.

The main ingredient for glass making is the silicon oxide or silica and it varies based on the type of glass to be made. The results in table I show, the chemical 
contents analyzed for the silica sand samples obtained from the two different rivers. The percentages of the silica sand are $77.60 \%$ for Yazaram and $77.70 \%$ for Mugulbu in Mubi South as shown in Table 1, which are high and adequate for glass making [7]. However, the percentage of iron oxide obtained is high and can only be suitable for coloured and amber glass [12].This is because the iron content is greater than $1 \%$. The percentage of the entire main ingredient $(\mathrm{MgO}, \mathrm{CaO}$ and $\mathrm{Al}_{2} \mathrm{O}_{3}$ ) obtainable in the silica sand samples as shown in table I were very low for glass making when compared with the standard percentage composition requirements. For example between $4-5 \%$ of $\mathrm{CaO}$ and $\mathrm{MgO}$ are required for soda lime and lead glasses manufacturing. However, the two samples can be used for borosilicate, fibre glasses and to some extent alumina silicate glasses, since the chemical composition by weight were obtained as $\mathrm{K}_{2} \mathrm{O} 7.58$, 7.44 and $\mathrm{Na}_{2} \mathrm{O}$ 6.23, 3.21 for Mugulbu and Yazaram respectively, which fall within the range of $2-9 \%$ by weight of $\mathrm{Na}_{2} \mathrm{O}$ and $\mathrm{K}_{2} \mathrm{O}$ [13].

Table 1: Shows the Chemical Compositions of the

Silica Sand Samples of, Mugulbu and Yazaram

\begin{tabular}{llll}
\hline $\mathrm{S} / \mathrm{N}$ & Composition & $\begin{array}{l}\text { Mugulbu \% } \\
\text { by Weight }\end{array}$ & $\begin{array}{l}\text { Yazaram\% by } \\
\text { Weight }\end{array}$ \\
\hline 1 & $\mathrm{Al}_{2} \mathrm{O}_{3}$ & 7.90 & 8.06 \\
2 & $\mathrm{SiO}_{2}$ & 77.70 & 77.60 \\
3 & $\mathrm{~K}_{2} \mathrm{O}$ & 7.58 & 7.44 \\
4 & $\mathrm{CaO}$ & 0.22 & 0.22 \\
5 & $\mathrm{TiO}_{2}$ & 0.20 & 0.14 \\
6 & $\mathrm{Cr}_{2} \mathrm{O}_{2}$ & 0.07 & 0.08 \\
7 & $\mathrm{MnO}_{8}$ & 0.02 & 0.03 \\
9 & $\mathrm{Fe}_{2} \mathrm{O}_{3}$ & 1.94 & 1.05 \\
10 & $\mathrm{CUO}$ & 0.009 & 0.007 \\
11 & $\mathrm{ZnO}_{12}$ & 0.03 & 0.04 \\
13 & $\mathrm{Sa}_{2} \mathrm{O}_{3}$ & $\mathrm{ND}$ & $\mathrm{ND}$ \\
14 & $\mathrm{RB}_{2} \mathrm{O}$ & $\mathrm{ND}$ & $\mathrm{ND}$ \\
15 & $\mathrm{BaO}_{16}$ & 0.04 & 0.03 \\
17 & $\mathrm{Nb}_{2} \mathrm{O}_{5}$ & 0.04 & 0.05 \\
18 & $\mathrm{ZrO}_{2}$ & 0.19 & 0.22 \\
19 & $\mathrm{Na}_{2} \mathrm{OU}$ & 0.01 & $\mathrm{ND}$ \\
20 & $\mathrm{Na}_{2} \mathrm{O}$ & 6.23 & 0.02 \\
21 & $\mathrm{MgO}$ & $\mathrm{ND}$ & 3.21 \\
\hline
\end{tabular}

Key: $N D=$ not detected

Grain morphology or shape, specific gravity (SPG) and the grain fitness number (GFN) are the physical properties of silica sand that determine the suitability of silica sand for glass making. The grain morphology for the two samples is angular as shown in table II.
According to [5], the grain shape or morphology must be angular rather than rounded. Also the specific gravity for the two samples is 2.50. According to [9], for silica sand with specific gravity greater than 2.65 is not suitable for glass making. Thus, all the two samples are suitable for glass making when compared with the standard requirements for glass making.

Table 2: Physical Properties of the Two Silica Sand Samples Yazaram and Mugulbu

\begin{tabular}{llll}
\hline S/N & Composition & Mugulbu & Yazaram \\
\hline 1 & Grain morphology & Angular & Angular \\
2 & $\begin{array}{l}\text { Specific gravity } \\
\text { (SPG) }\end{array}$ & 2.50 & 2.50 \\
3 & $\begin{array}{l}\text { Grain fitness } \\
\text { number (GFN) }\end{array}$ & 23.67 & 8.77 \\
\hline
\end{tabular}

From the results of particle size distribution, shown in Table 3. All the two samples were found to be suitable for glass making, because over $90 \%$ of the particle size lie within 15-100 mesh (BS sieve number) $[1,14]$.

Table 3: The calculated cumulative percentage weight of the silica sand particles passing each sieve aperture for the two samples Yazaram and Mugulbu

\begin{tabular}{llllll}
\hline $\begin{array}{l}\text { Sieve } \\
\text { Aperture }\end{array}$ & $\begin{array}{l}\text { Mesh } \\
\text { Number }\end{array}$ & Yazaram & Product & Mugulbu & Product \\
\hline 1.40 & 14 & 52.10 & - & 25.00 & - \\
1.00 & 18 & 21.51 & 301.14 & 16.99 & 237.85 \\
0.71 & 25 & 15.31 & 277.02 & 16.72 & 300.96 \\
0.50 & 35 & 8.05 & 201.25 & 14.00 & 350.00 \\
0.355 & 45 & 2.41 & 84.35 & 11.29 & 395.15 \\
0.250 & 60 & 0.22 & 9.90 & 8.43 & 379.35 \\
0.180 & 80 & 0.01 & 0.60 & 3.29 & 197.40 \\
0.125 & 120 & - & - & 2.26 & 180.80 \\
0.090 & 170 & - & - & 0.80 & 96.00 \\
0.063 & 230 & - & - & 0.33 & 56.10 \\
0.063 & -230 & - & - & 0.73 & 169.90 \\
& & 99.69 & 874.26 & 99.84 & 2363.51 \\
\hline
\end{tabular}

\section{CONCLUSION}

The percentage of silica content which is the major glass forming oxide in the two samples obtained as $77.60 \%$ and $77.70 \%$ for Yazaram and Mugulbu respectively were found adequate for glass making because the percentage values lie within the minimum standard requirements of $70 \%$. Both the silica sand samples have the physical properties that met the requirements for the manufacture of glass since the grain morphology is angular rather than rounded. The percentage of iron oxide in the silica sand samples obtained as $1.94 \%$ and $1.05 \%$ for Mugulbu and Yazaram respectively were a little bit higher than $1 \%$, for this reason, it limits its applications to coloured 
and amber glass production. The two samples analyzed have additional chemicals or compounds that could be added to improve the quality of the glass produced. Therefore, the silica sand samples investigated are adequate for glass manufacturing and therefore, should be utilized.

\section{REFERENCES}

[1] BS2975 "British Standard Methods for Sampling and Analysis of Glass-Making Sands" www.Britannica.com, accessed on sept.29, 2011.

[2] Raw Materials Research and Development Council (RMRDC), Federal Ministry of Science and Technology, Multi - Disciplinary Task Force - report of the Techno-Economy Survey on Non-Metallic Mineral Products Sector, $3^{\text {rd }}$ Update Abuja, Nigeria. Pp 14 - 15 and 49, 2001

[3] George.R. "Substances Used in the Making of Coloured Glass" www.britglass.org.uk/history-glass,accessed Augt.4, 2011.

[4] David, M. I . "A Study of Silica Sand Quality and End Uses in Surrey and Kent" www.Ist-glass.Istthings.com/articles/glass colouring.html, accessed july.12, 2011.

[5] Waudby, J.E. "A Summary of the Known Deposit of Glass in Nigeria" www.fao.org/decrep/005/ac6726 Lac672b/6.htm, (Access August 04, 2011).
[6] BGS "British Geological Survey, Silica Sand Supply Chain.UK" www.mineralszone.com/ minerals/ silica.html, accessed on sept.29, 2011.

[7] BGMC "British Glass Manufacturers Confederation, 9 Churchill Way" Chapeltown, Sheffield, South Yorkshire, 5352PY.uk.www.britglass.org.uk/typesglass, Accessed on Sept. 29, 2011.

[8] Powers, .M. C. A New Roundness Scale for Sedimentary Particles. John Willey and Sons Inc. New York, 1983.

[9] Tooley, F. V. Hand Book of Glass Manufacturing. 2nd Edition, Ogden Press, New York, 1989

[10] National Metallurgical Development Centre (NMDC) Jos, Plateau State, Nigeria, 2011.

[11] Head, K. H. Manual of Soil Laboratory Testing. Pentech Press. London, 1992.

[12] Sintali, I. S and Egbo, G. "Investigation on the Chemical and Physical Properties of Dapchi, Ngala and Gwoza Silica Sand for Glass Making" Journal of Engineering and Technology (JET) Vol. 2, No. 2, Bayero University Kano, Nigeria, 2007.

[13] Manas, C. Science of Engineering Materials. Macmillan Company Publishers India, 1979.

[14] Idehai, I. M, Egai A. O. and Okiotor, M. E, "Comparative Analysis of Geotechnical Properties of REsu=idual Soils in part of Awka and Abuja Areas of Nigeria, Nigerian Journal of Technology, Vol. 34, No. 4, October 2014, pp $595-603$ 